\title{
Post-partum pelvic floor dysfunction assessed on 3D rotational ultrasound: a prospective study on women with first- and second-degree perineal tears and episiotomy
}

\author{
Martina Leombroni ${ }^{a}$, Danilo Buca ${ }^{a}$ (D) Marco Liberati ${ }^{a}$, Eleonora Falò ${ }^{a}$, Giuseppe Rizzo ${ }^{b, c}$ (D), Asma Khalil ${ }^{d}$, \\ Lamberto Manzoli ${ }^{e}$, Maria Elena Flacco ${ }^{f}$, Alessandro Santarelli ${ }^{a}$, Alexander Makatsariya ${ }^{c}$ (D), \\ Franco Frondaroli ${ }^{\mathrm{a}}$ and Francesco D'Antonio ${ }^{\mathrm{g}, \mathrm{h}}$ \\ ${ }^{\mathrm{a} D e p a r t m e n t}$ of Obstetrics and Gynaecology, University of Chieti, Chieti, Italy; ${ }^{\mathrm{b}}$ Department of Maternal Fetal Medicine, Ospedale \\ Cristo Re Roma, University of Roma Tor Vergata, Rome, Italy; 'Department of Obstetrics and Gynaecology, The First I.M. Sechenov \\ Moscow State Medical University, Moscow, Russia; ${ }^{\text {'}}$ Fetal Medicine Unit, Division of Developmental Sciences, St. George's University

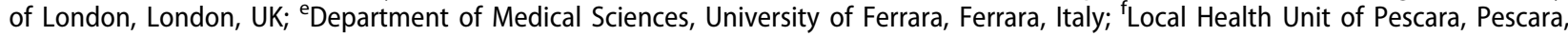 \\ Italy; ${ }^{9}$ Women's Health and Perinatology Research Group, Department of Clinical Medicine, Faculty of Sciences, Women'S Health and \\ Perinatology Research Group, UiT - The Arctic University of Norway, Tromsø, Norway; ${ }^{\mathrm{h}}$ Department of Obstetrics and Gynaecology, \\ University Hospital of Northern Norway, Tromsø, Norway
}

ABSTRACT

Purpose: To evaluate the morphology and biometry of pelvic floor structures 3 months after birth in women experiencing first- or second-degree perineal tears or undergoing episiotomy during labor.

Material and methods: Prospective observational study including nulliparous women delivering at term with a clinical diagnosis of first- or second-degree perineal tears after birth or undergoing episiotomy. The role of Kristeller maneuver during labor in affecting pelvic structure and function is also explored. All women underwent 2D trans-perineal and 3D endovaginal or endoanal ultrasound 3 months after birth.

Results: 115 women assessed 3 months after delivery were enrolled in the study. Compared with controls, women who experienced first-degree perineal tears had higher bladder neck-symphysis (versus $20.9 \pm 4.9$ versus $16.1 \pm 4.9 \mathrm{~mm}, p=.017$ ), bladder wall-pubic symphysis (22.4 \pm 7.4 versus $14.2 \pm 9.5 \mathrm{~mm}, \quad p=.02)$ and anorectal angle-symphysis distance $(12.5 \pm 4.7$ versus $9.3 \pm 4.3 \mathrm{~mm}, p=.018$ ). Furthermore, they have thicker internal and external anal sphincter. The incidence of partial right and left pubo-rectalis muscle avulsion was higher in women experiencing first-degree vaginal tear during labor ( 16.2 versus $0 \%, p=.004$ for both). In women affected by second-degree tears, the occurrence of partial avulsion of the right and left pubo-rectalis muscle was $16.2 \%$, while Oasis was detected in $10.8 \%$ of the cases. Women receiving Kristeller maneuver during labor had a higher incidence of either right or left puborectalis muscle avulsion.

Conclusion: Women who had either first- and second-degree perineal tears or episiotomy show signs of abnormal pelvic morphometry on 3D rotational ultrasound 3 months after birth.
ARTICLE HISTORY

Received 22 February 2019

Revised 3 April 2019

Accepted 17 April 2019

KEYWORDS

3D pelvic floor ultrasound; episiotomy; Kristeller maneuver; levator ani muscle; perineal tears; postpartum pelvic floor dysfunction

\section{Introduction}

Pelvic floor dysfunction (PFD) encompasses a heterogeneous group of conditions characterized by anatomical or functional anomalies of pelvic floor structures, such as pelvic organ prolapses (POP), urinary (UI), and anal incontinence (Al) [1-6].

PFD has a relevant impact on women's physical, social, psychological, and sexual life. It has been estimated that about a third of the world's female population will suffer from PFD during their lifetime [7-8]. In 2010, 28 million women in the USA presented with PFD, and it is believed that this number may increase to 43 million by $2050[9,10]$.

A large variety of risk factors for PFD have been described in the published literature, including vaginal delivery, advanced maternal age, prolonged second stage of labor, large fetal head circumference, episiotomy, and perineal tears [11].

CONTACT Francesco D'Antonio francesco.dantonio@uit.no Department of Clinical Medicine, Faculty of Health Sciences, UiT - The Arctic University of Norway, Hansine Hansensveg 18, Troms $\varnothing$, Norway

(-) Supplemental data for this article is available online at https://doi.org/10.1080/14767058.2019.1609932.

(C) 2019 Informa UK Limited, trading as Taylor \& Francis Group 
Among the relevant pelvic structures, levator ani muscle (LAM) plays a major role in maintaining the structural and functional integrity of the pelvic floor. LAM is significantly stretching during vaginal delivery in order to allow the fetus to progress through the birth canal [12-17].

The LAM might be exposed to trauma because of stretching or disconnection of the pubo-visceralis muscle (PVM) from its insertion on the inferior pubic ramus and pelvic walls $[13,18]$.

A number of etiologies of PFD have been proposed, including mechanical damage, obstetric-associated denervation, ischemia and reperfusion injury, and defective soft tissue remodeling [11].

While assessment of pelvic floor structures after delivery involves clinical and instrumental examination, such as ultrasound and magnetic resonance imaging [19,20], prediction of PFD is challenging. Advances in pelvic imaging techniques and the advent of three-dimensional pelvic floor ultrasound (3D pfu) have been suggested to improve anatomical and functional assessment of pelvic structures in women with deep infiltrating endometriosis and therefore has the potential to identify those women at higher risk of PFD after delivery [21-26].

The aim of this study was to evaluate the morphology and biometry of pelvic floor structures using endovaginal and endoanal 3D rotational ultrasound, 3 months after birth, in women experiencing first-, second-degree perineal tears, or undergoing episiotomy during labor.

\section{Materials and methods}

This was a prospective observational study carried out in a dedicated post-partum clinic 3 months after birth at the Department of Obstetrics and Gynecology of SS Annunziata University Hospital in Chieti from 2016.

The inclusion criteria were nulliparous women who delivered at or beyond 37 weeks of gestation and had a clinical diagnosis of first- or second-degree perineal tears after birth or had indicated episiotomy during labor. The exclusion criteria were multiple pregnancies, maternal age less than 18 years, fetal macrosomia, birth complicated by third- or fourth-degree perineal tears, median episiotomy, previous vaginal tears, perineal, or pelvic surgery. The study population was compared with healthy controls, defined as nulliparous women who had uneventful vaginal birth without episiotomy and who did not experience any form of perineal tear. For the purpose of the analysis, only women with medio-lateral episiotomy were included in the analysis.

MOOSE guidelines for observation studies were followed. Written informed consent was obtained from each woman before assessment. The Regional Ethical Review Board approved the study (reference number 2014/521 LP12).

Immediately before the examination, a researcher recorded the obstetric history using a standardized research protocol (parity, medication, contraceptives, breastfeeding, day of menstrual cycle, and gynecological operations). The demographic and obstetric details were also crosschecked from the hospital records. Pelvic pain, dyspareunia, Al, and UI were also evaluated. The ultrasound examiner (ML) was blinded to pregnancy outcome ad intra-partum details of all the study participants.

\section{Ultrasound technique}

All women underwent 2D trans-perineal ultrasound (2D TPUS), 3D endovaginal ultrasound (3D EVUS), and 3D endoanal ultrasound (3D EAUS) using a BK Medical Flex Focus 400. 2D TPUS exam was performed using Curved Array 8823 transducer (B-K Medical, Herlev, Denmark). The ultrasonographic exam was performed with patient placed in dorsal lithotomy position, with hips flexed and abducted. During 2D TPUS (16), the midsagittal plane (Figure 1) was used to identify all anatomical structures between the posterior surface of the pubic symphysis and the posterior part of the LAM (bladder, urethra, vaginal walls, anal canal, and rectum) $[25,27]$. The convex transducer was gently positioned on the perineum between the mons pubis and the anal canal with a small pressure, in order to avoid false-negative results [21]. Assessment of the anterior compartment included the measure of

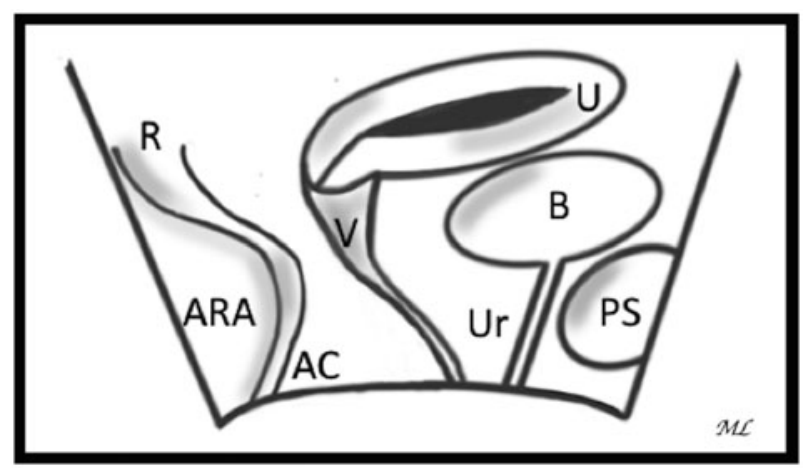

Figure 1. 2D-TPUS midsagittal view (schematic drawing). From left to right, PS: pubic symphysis; B: bladder; Ur: urethra; U: uterus; V: vagina; Acta Anal Canal, ARA: Anorectal Angle; $\mathrm{R}$ : rectum. 
bladder-symphysis distance, bladder neck-symphysis distance, and the retro-vesical angle (at rest and under valsalva maneuver) in order to valuate organs descent [16]. Moreover, bladder wall thickness and postvoid residual bladder volume were also evaluated. Descent of pelvic organs was calculated based on the difference, at rest and under valsalva maneuver, of the distance toward the organs and a reference line parallel to the infero-posterior margin of the pubic symphysis. Compared with TVS, TPUS is more likely to allow full development of prolapse and has the advantage of including a fixed point of reference, the lower symphyseal margin, in the field of view [21].

Hypermobility of the urethra was defined as a difference between bladder-symphysis distance at rest and under valsalva more than $25 \mathrm{~mm}$ [27]. We adopted a cut-off of $>5 \mathrm{~mm}$ and $>120$ for defining an abnormal wall thickness and retro vesical angle, respectively $[28,29]$.

The posterior compartment was also evaluated by examining the descent of anorectal angle (anorectal angel-symphysis distance at rest and under valsalva maneuver).

High-frequency 3D-EVUS (endo-vaginal US) and 3DEAUS (endo-anal US) were performed with a 2050 probe with a $9-16-\mathrm{MHz} 360^{\circ}$ rotational scanner (B-K Medical, Herlev, Denmark), following a standardized approach. The 2050 transducer in characterized by a $3 \mathrm{D}$ motorized system that allows acquisition of 300 trans axial images over a distance of $60 \mathrm{~mm}$ in $60 \mathrm{~s}$ [22]. The images of pelvic floor muscle subdivision, obtained with 3D-EVUS, exhibit very good cadaveric anatomical correlation.

During 3D-EVUS, Santoro et al. described four levels of assessment in the axial plane [22]. In Level III, the LAM can be completely visualized as a multilayer hyperechoic sling from the inferior pubic rami, going laterally to the vagina and reaching the anal canal (Figure 2).

After having acquired the 3D volume, in the Level III (the axial plan), the following measurements were taken: minimal hiatal area and PVM thickness of the left (at 3 o'clock) and right (at 9 o'clock) branch [2,17]. Moreover, the presence of LAM avulsion was also investigated.

The minimal hiatal area, according to Santoro et al., was calculated as the area within the LAM inner perimeter enclosed by the inferior edge of the pubic symphysis and the inferior pubic rami [21].

LAM avulsion, investigated with 3D EVUS moving the cube slightly in the axial plane, is defined as a discontinuity between the inferior pubic rami and the

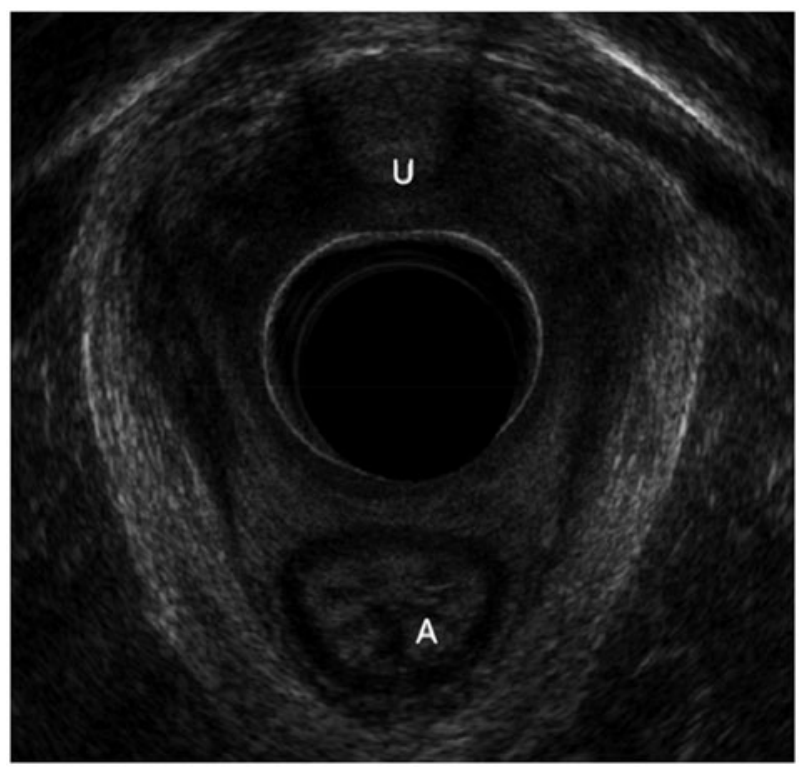

Figure 2. Pelvic floor three-dimensional transvaginal ultrasound (obtained with a $360^{\circ}$ rotational transducer) 3 months after delivery. The Levator Ani Muscle (LAM) is visualized as a multilayer hyperechoic sling. (A) Anal canal. (B) Urethra.

muscle. The absence of avulsion was evaluated in case of complete attachment of the muscle to the pubic bone. Complete avulsion was diagnosed in case of entirely detached of LAM from the pubic bone, while partial avulsion in case of minor muscle injuries [30].

Measurements of levator hiatus parameters by 3DTVS showed good to excellent interobserver (intraclass correlation coefficient (ICC), 0.655-0.889) and interdisciplinary (ICC, 0.639-0.915) repeatability [31].

During 3D EAUS, any defects of the internal anal sphincter (IAS) or the exsternal anal sphincter (EAS) were noted, in order to diagnose Occult Obstetrics Anal Sphincter Injuries (OASIS) [22,32].

Offline analysis for all recorded volumes was conducted using B-K Medical Viewer version 7.0.0.519. Every measurement was collected three times in order to ascertain intraobserver variability (Figures 3-5).

\section{Statistical analysis}

The association between selected maternal and gestational characteristics and each of the explored outcomes was initially evaluated with standard univariate analyses. Chi-squared test, $t$-test, and Kruskall-Wallis test were used for categorical variables, normally distributed and non-normally distributed continuous variables, respectively (normality was assessed with the Shapiro-Wilk test).

The potential independent predictors of each outcome were then evaluated using multivariate logistic regression, and four separate models were fit. 


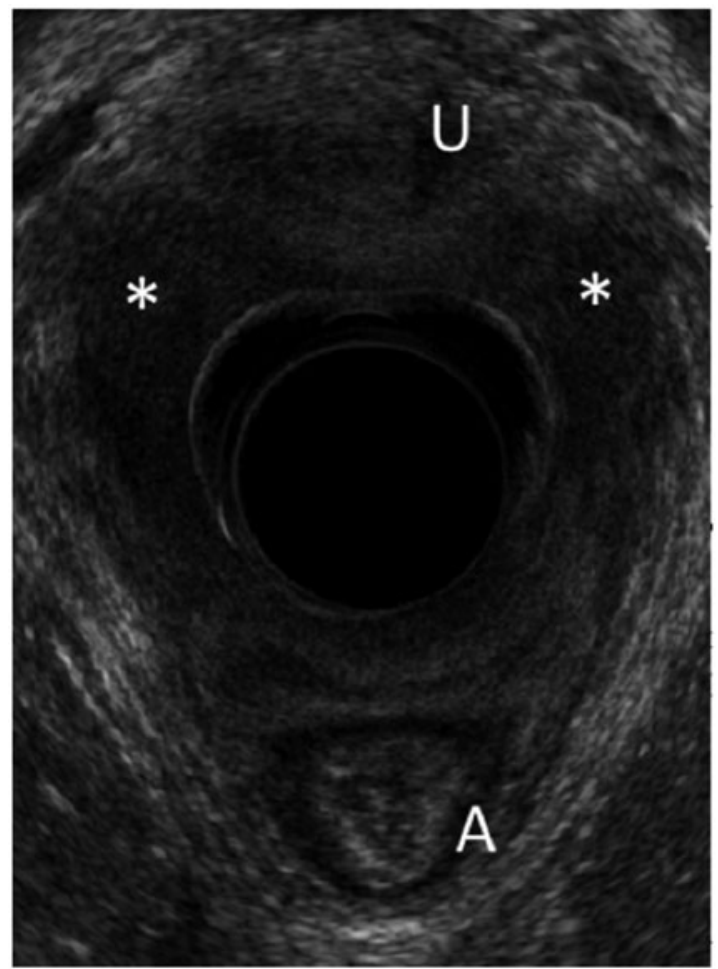

Figure 3. Pelvic floor three-dimensional transvaginal ultrasound (obtained with a $360^{\circ}$ rotational transducer) 3 months after delivery. The Levator Ani Muscle (LAM) is visualized as a multilayer hyperechoic sling. The site of partial avulsion of pubo-rectalis muscles is the hypoechoic area signed with *. (A) Anal canal. (B) Urethra.

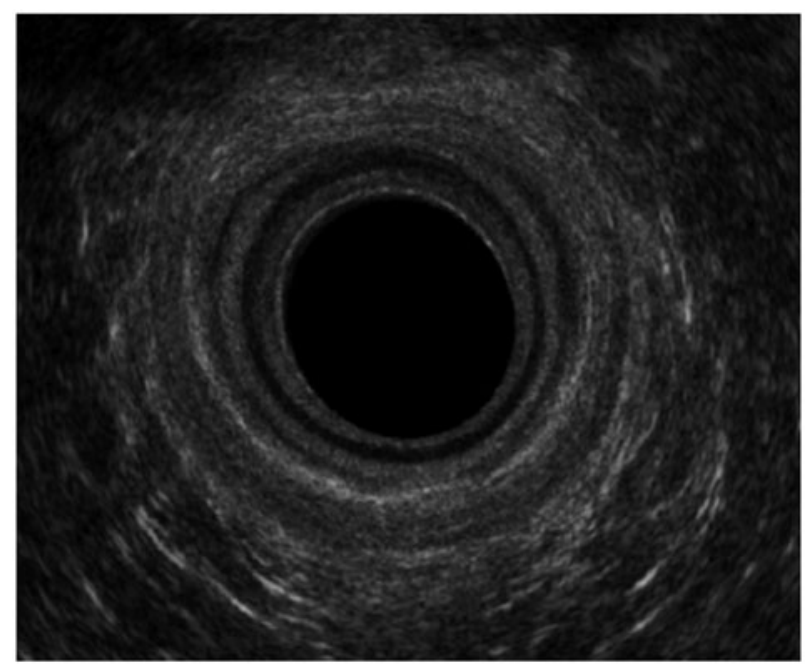

Figure 4. Endoanal three-dimensional transvaginal ultrasound (obtained with a $360^{\circ}$ rotational transducer) 3 months after delivery.

To reduce potential overfitting, all the explored variables were tested for inclusion in the final model, but the overall number of covariates was limited to $1 / 10$ of the outcomes in all phases of model fitting. Additionally, for all the explored outcomes, the

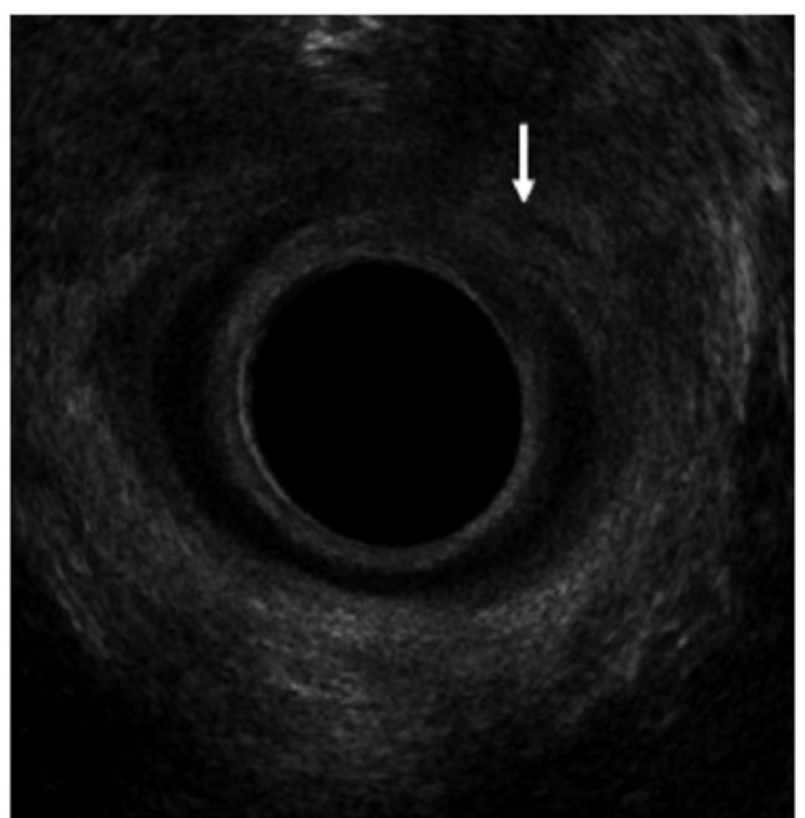

Figure 5. Endoanal three-dimensional transvaginal ultrasound (obtained with a $360^{\circ}$ rotational transducer) 3 months after delivery. OASIS is signed with narrow.

potential independent predictors were analyzed using a polytomous logistic model. For each predictor variable, two odds ratios (ORs) were, therefore, obtained, the first for the comparison of women with seconddegree vaginal tear versus women with first-degree vaginal tear, the second for the comparison of women with episiotomy versus women with first-degree vaginal tear. The goodness-of-fit was checked using the Hosmer-Lemeshow test, and the predictive power assessed through C-statistics (area under the receiving operator curve). Standard postestimation tests were used to check the final model validity, performing multicollinearity and influential observation analyses (using standardized residuals, change in Pearson, and deviance chi-square).

To further explore the relationship between each outcome and the onset of pelvic floor trauma at delivery, four additional univariate analyses were run, using the same approach previously described. In each analysis, several ultrasound pelvic parameters compared between (1) women with first-degree vaginal tear and women with second-degree vaginal tear; (2) women with first-degree vaginal tear and women undergoing episiotomy; (3) women with second-degree vaginal tear and women undergoing episiotomy; (4) controls. Furthermore, we explored the differences in each of the ultrasound measurements in women undergoing Kristeller maneuver and women not undergoing Kristeller maneuver during delivery.

Finally, the distribution of selected ultrasonographic indexes of damage was separately evaluated in the 
Table 1. Overall characteristics of the sample and univariate analyses evaluating the relationship between the recorded maternal and gestational characteristics and each outcome.

\begin{tabular}{|c|c|c|c|c|c|c|c|c|c|}
\hline & $\begin{array}{l}\text { Overall } \\
(n=104)\end{array}$ & $\begin{array}{l}\text { Episiotomy } \\
\qquad(n=30)\end{array}$ & $p^{\mathrm{a}}$ & $\begin{array}{c}\text { First-degree } \\
\text { vaginal } \\
\text { tear }(n=21)\end{array}$ & $p^{\mathrm{a}}$ & $\begin{array}{c}\text { Second-degree } \\
\text { vaginal } \\
\text { tear }(n=37)\end{array}$ & $p^{\mathrm{a}}$ & $\begin{array}{c}\text { Kristeller } \\
\text { maneuver } \\
(n=31)\end{array}$ & $p^{\mathrm{a}}$ \\
\hline $\begin{array}{l}\text { Mean maternal age in } \\
\text { years }(S D)\end{array}$ & $32.2(4.7)$ & $32.0(4.2)$ & .8 & $34.0(4.6)$ & .06 & $31.8(4.8)$ & .5 & $31.2(4.4)$ & .15 \\
\hline Mean BMI (SD) & $22.9(3.5)$ & $23.0(3.9)$ & .9 & $22.2(3.2)$ & .3 & $23.7(3.1)$ & .09 & $23.3(4.0)$ & .4 \\
\hline Cigarette smoking, \% & 17.3 & 10.0 & .2 & 28.6 & .13 & 10.8 & .19 & 12.9 & .4 \\
\hline $\begin{array}{l}\text { Mean gestational age at birth } \\
\text { in weeks (SD) }\end{array}$ & $39.4(1.3)$ & $39.5(1.1)$ & .8 & $39.1(1.6)$ & .2 & $39.5(1.3)$ & .7 & $39.2(1.4)$ & .3 \\
\hline Previous abdominal surgery, $\%$ & 21.2 & 23.3 & .7 & 19.1 & .8 & 21.6 & .9 & 19.4 & .8 \\
\hline $\begin{array}{l}\text { Incontinence during preg- } \\
\text { nancy, } \%\end{array}$ & 13.5 & 13.3 & .9 & 9.5 & .6 & 13.5 & .9 & 19.4 & .3 \\
\hline Post-partum incontinence, \% & 30.8 & 26.7 & .6 & 38.1 & .4 & 32.4 & .8 & 22.6 & .2 \\
\hline $\begin{array}{l}\text { Severe constipation during } \\
\text { pregnancy, \% }\end{array}$ & 21.2 & 16.7 & .5 & 19.1 & .8 & 27.0 & .3 & 19.4 & .8 \\
\hline Fluid intake $<1.5 \mathrm{~L} / \mathrm{d}, \%$ & 47.1 & 43.3 & 6 & 61.9 & .13 & 46.0 & .9 & 45.2 & .8 \\
\hline $\begin{array}{l}\text { Weight increase during preg- } \\
\text { nancy }>14 \mathrm{~kg}, \%\end{array}$ & 44.2 & 46.7 & .7 & 28.6 & .11 & 54.0 & .13 & 54.8 & .16 \\
\hline Ano-vulvar distance $>2 \mathrm{~cm}, \%$ & 12.5 & 16.7 & .4 & 4.8 & .2 & 13.5 & .8 & 19.4 & .17 \\
\hline Operative delivery, \% & 8.7 & 20.0 & .009 & 0.0 & .11 & 8.1 & .9 & 19.4 & .011 \\
\hline Fetal macrosomy, $\%$ & 1.9 & 0.0 & .4 & 0.0 & .5 & 2.7 & .7 & 3.2 & .5 \\
\hline $\begin{array}{l}\text { Kristeller maneuver during } \\
\quad \text { delivery, \% }\end{array}$ & 29.8 & 66.7 & $<.001$ & 14.3 & .08 & 18.9 & .07 & - & \\
\hline
\end{tabular}

${ }^{a}$ Chi-squared test for categorical variables; $t$-test for continuous ones. All $p$ values are referred to the comparison between the women with or without the selected outcome: e.g. those undergoing an episiotomy during delivery versus those not undergoing an episiotomy. For most of the recorded variables, the values observed in the group experiencing the outcome were very similar to the values in the group not experiencing the outcome: therefore, only the first were reported to avoid redundancy.

subsample of women experiencing some form of pelvic floor trauma (e.g. women reporting either puborectalis muscle avulsion, levator ani muscle damage, Obstetric Anal Sphincter Injures - Oasis, or asymmetry). However, given the low number of women included, no univariate analyses were run, and data were reported only for descriptive purposes.

Statistical significance was defined as a two-sided $p$-value $<.05$, and all analyses were carried out using Stata, version 13.1 (Stata Corp, College Station, TX, 2013).

\section{Results}

One hundred fifteen women assessed 3 months after delivery were enrolled in the study. General characteristics of the population analyzed in the study are reported in Table 1 . The mean maternal age was $32.2 \pm 4.7$ years, the mean maternal BMI was $22.9 \pm 3.5$, while the mean gestational age at birth was $39.4 \pm 1.3$ weeks. Among the women included nine $(8.7 \%)$ had an operative delivery with vacuum (Kiwi Complete Vacuum Delivery System). Twenty-one women with first, 37 with second-degree perineal tears, 31 who underwent episiotomy during labor and 26 controls.

$\mathrm{UI}$ was reported in 13.5 and $30.8 \%$ of women, respectively, during pregnancy and post-partum. One woman denounced post-partum $\mathrm{Al}$ and $6.8 \%$ urinary retention. Finally, pelvic pain and dyspareunia was, respectively, reported in 8.5 and $35.6 \%$ of patients.
Women who experienced first-degree perineal tears had higher bladder neck-symphysis (versus $20.9 \pm 4.9 \mathrm{~mm}$ versus $16.1 \pm 4.9 \mathrm{~mm}, p=.017$ ), bladder wall-pubic symphysis $(22.4 \pm 7.4 \mathrm{~mm}$ versus $14.2 \pm 9.5 \mathrm{~mm}, p=.02$ ), and anorectal angle-symphysis distance $(12.5 \pm 4.7 \mathrm{~mm}$ versus $9.3 \pm 4.3 \mathrm{~mm}, p=.018)$ compared to control. Furthermore, they have thicker internal $(2.2 \pm 0.4 \mathrm{~mm}$ versus $2.6 \pm 0.7 \mathrm{~mm}, p=.02)$ and external $(2.4 \pm 0.6 \mathrm{~mm}$ versus $3.3 \pm 0.6 \mathrm{~mm}, p=.0001)$ anal sphincter. The incidence of right and left puborectalis muscle avulsion was higher in women experiencing compared to those not experiencing firstdegree vaginal tear during labor (16.2 versus $0 \%$, $p=.004$ for both). There was no difference in all the other ultrasound measurements explored in the present study among these two groups.

Women experiencing second-degree perineal tears during labor had a ticker of internal $(2.5 \pm 0.6 \mathrm{~mm}$ versus $2.2 \pm 0.4 \mathrm{~mm}, p=.011)$ and external $(3.1 \pm 1.1 \mathrm{~mm}$ versus $2.4 \pm 0.6 \mathrm{~mm}, p=.006$ ) anal sphincter compared with controls. Furthermore, in women affected by second-degree tears, the occurrence of avulsion of the right and left pubo-rectalis muscle was $16.2 \%$, while Oasis was detected in $10.8 \%$ of the cases.

The internal anal sphincter was thicker in women undergoing episiotomy compared to control $(2.4 \pm 0.7 \mathrm{~mm}$ versus $2.2 \pm 0.4 \mathrm{~mm})$ but this difference did not reach statistical significance $(p=.132)$, while the thickness of the external anal sphincter was significantly higher in women with episiotomy $(3.5 \pm 1.6 \mathrm{~mm}$ 
Table 2. Multivariate analyses evaluating the potential predictors of each recorded outcome.

\begin{tabular}{|c|c|c|c|c|c|c|c|c|}
\hline & \multicolumn{2}{|l|}{ Episiotomy } & \multicolumn{2}{|c|}{ First degree vaginal tear } & \multicolumn{2}{|c|}{ Second degree vaginal tear } & \multicolumn{2}{|l|}{ Kristeller maneuver } \\
\hline & Adjusted OR $(95 \% \mathrm{Cl})$ & $p$ & Adjusted OR $(95 \% \mathrm{Cl})$ & $p$ & Adjusted OR (95\% Cl) & $p$ & Adjusted OR (95\% Cl) & $p$ \\
\hline $\begin{array}{l}\text { Mean maternal age in years, } \\
1 \text {-year increase }\end{array}$ & $1.00(0.90-1.13)$ & .9 & $1.10(0.98-1.23)$ & .10 & $0.95(0.87-1.04)$ & .3 & $0.90(0.81-0.99)$ & .033 \\
\hline Fetal macrosomy & $--^{a}$ & - & $-{ }^{\mathrm{a}}$ & - & $2.28(0.13-40.2)$ & 6 & $2.62(0.15-45.7)$ & .5 \\
\hline Operative delivery & $3.27(0.54-19.7)$ & .19 & $-{ }^{a}$ & - & $1.73(0.34-8.73)$ & .5 & $9.54(1.97-46.3)$ & .005 \\
\hline Kristeller maneuver & $10.3(3.62-29.1)$ & $<.001$ & $0.37(0.10-1.40)$ & .14 & $0.34(0.12-0.98)$ & .047 & - & - \\
\hline
\end{tabular}

OR: odds ratio; $\mathrm{Cl}$ : confidence interval.

${ }^{a}$ Not included in the final model due to the presence of zero observations in the group of women experiencing the outcome.

versus $2.4 \pm 0.6 \mathrm{~mm}, p=.001)$. Likewise, there was no difference in the incidence of either right or left puborectalis muscle avulsion ( $p=.27$ ) (Table 2).

Supplementary Table 4 shows the comparison between the different continuous ultrasound pelvic parameters in women with episiotomy, first- and second-degree perineal tears.

The mean distance between bladder neck and pubic symphysis after valsalva maneuver was lower in women with second compared to those with first perineal tears $(16.6 \pm 5.7 \mathrm{~mm}$ versus $20.9 \pm 4.9 \mathrm{~mm}, p<.05)$. Mean distance between posterior bladder wall and pubic symphysis and that between anorectal angle and pubic symphysis were also lower in women with second-degree perineal tears $(27.5 \pm 6.4 \mathrm{~mm}$ versus $30.7 \pm 6.67 \mathrm{~mm}$ and $14.6 \pm 4.7$ versus $15.2 \pm 4.1 \mathrm{~mm}$, respectively, $p<.05$ ) (Table 3 ).

When comparing women with first-degree vaginal tear with those undergoing episiotomy, bladder-symphysis distance either at rest $(24.3 \pm 8.10 \mathrm{~mm}$ versus $30.7 \pm 6.67 \mathrm{~mm}, p<.05)$ and after valsalva maneuver $(14.7 \pm 8.8 \mathrm{~mm}$ versus $22.4 \pm 7.41 \mathrm{~mm}, p<.05)$ were significantly lower in women with episiotomy. Furthermore, women with episiotomy had a lower anorectal angle-symphysis distance after valsalva maneuver $(8.1 \pm 3.9 \mathrm{~mm}$ versus $12.5 \pm 4.7 \mathrm{~mm}, p<.05)$, while there was no difference in any of the ultrasound pelvic parameters assessed between women with second degree perineal tears and those with episiotomy, except for the presence of post-void residual urine in women the episiotomy group (24.1 versus $5.9 \%, p<.05$ ) (Table 3).

Finally, we assessed whether Kristeller maneuver was associated with any difference in pelvic morphometry. There was no difference for the large majority of the ultrasound pelvic parameters explored in the present study between women who compared to those who did not had Kristeller maneuver, except for presence of post void residual urine in women the Kristeller group ( 23.3 versus $4.8 \%, p=.008$ ) (Table 3 ). However, women receiving Kristeller maneuver during labor had a higher incidence of either right (29.0 versus $5.5 \%, p=.02)$ and left (25.8 versus $6.8 \%$, $p=.02$ ) puborectalis muscle avulsion compared (Table 4).

At univariate analysis, operative delivery $(p=.009)$ and Kristeller maneuver $(p<.0001)$ were independently associated with episiotomy, while this association was lost for first- and second-degree perineal tears. At multivariate analysis, Kristeller maneuver was associated with episiotomy with an OR of $10.3(95 \% \mathrm{Cl}$ 3.62-29.1, $p<.001$ ) (Table 2).

\section{Discussion}

The findings from this study showed that signs of abnormal pelvic floor morphometry and function can be detected on dedicated ultrasound in women experiencing first- or second-degree perineal tears 3 months after childbirth. Women who experienced firstdegree perineal tears had higher bladder neck-symphysis, bladder wall-pubic symphysis, anorectal anglesymphysis distance and thicker internal and external anal sphincter compared to controls, while women experiencing second-degree perineal tears during labor had a ticker of internal and external anal sphincter. More importantly, the incidence of LAM avulsion was higher in women with first- and second-degree perineal tears compared to controls. Women undergoing episiotomy had a ticker external anal sphincter, while there was no substantial difference in the incidence of LAM avulsion compared to controls. Finally, the incidence of LAM avulsion was higher in women receiving fundal pressure (Kristeller maneuver) during delivery.

This is, to our knowledge, the first study assessing the role of 3D rotational ultrasound in women presenting with perineal tears and episiotomy. Small sample size of the study, inclusion of only women with firstand second-degree perineal tears or episiotomy and lack of assessment with other imaging technique (i.e. magnetic resonance imaging) and long-term evaluation of pelvic structure and function are the main limitations of the present study. Furthermore, some of 


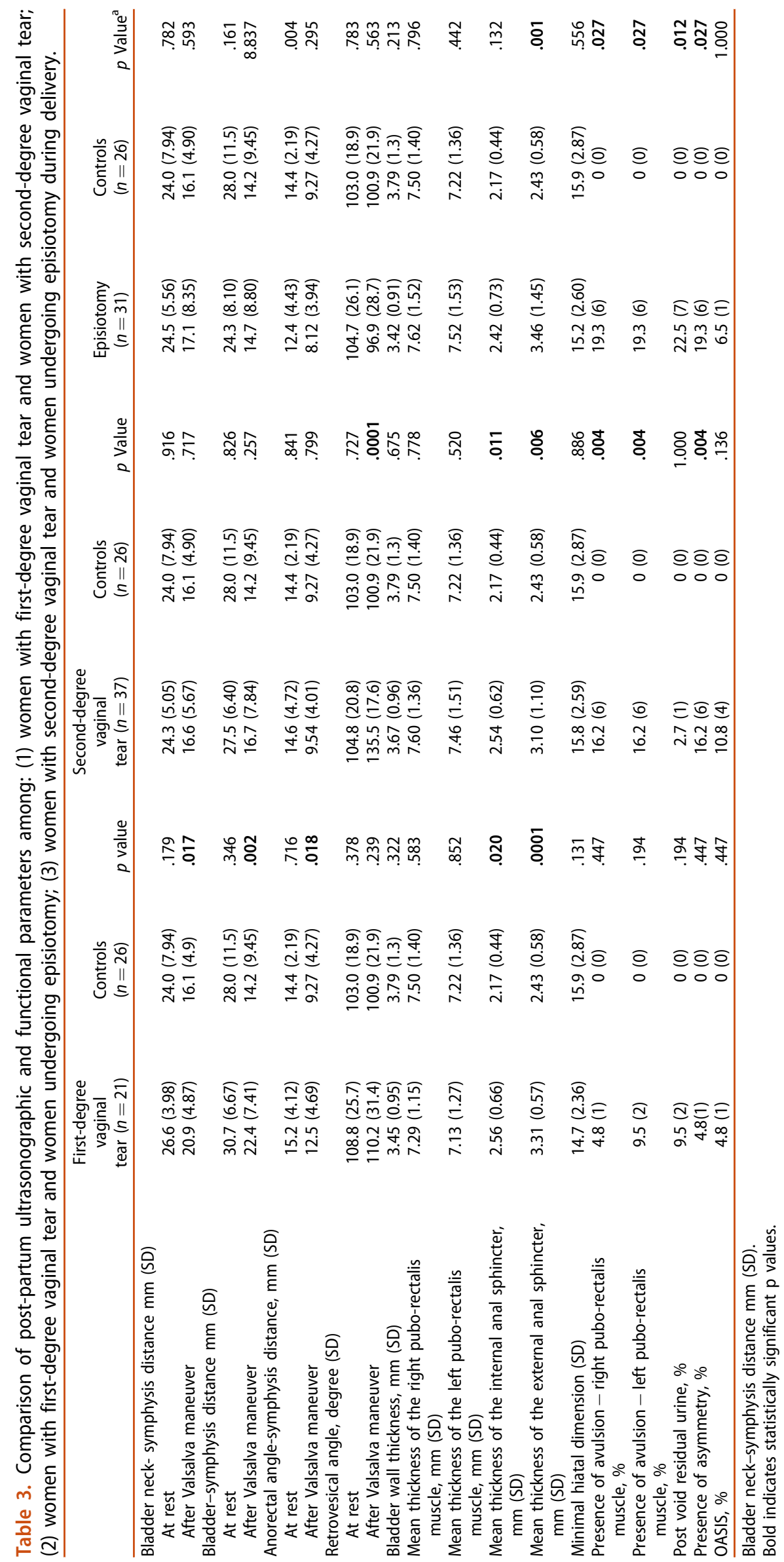


Table 4. Post-partum ultrasonographic and functional parameters in women receiving or not receiving Kristeller maneuver during delivery.

\begin{tabular}{lccc}
\hline & Kristeller $(n=31)$ & No Kristeller $(n=73)$ & $p^{\mathrm{a}}$ \\
\hline Bladder neck-symphysis distance, mm (SD) & & & \\
$\quad$ At rest & $25.2(5.06)$ & $24.6(5.85)$ & .6 \\
$\quad$ After Valsalva maneuver & $17.4(7.82)$ & $17.4(6.38)$ & .9 \\
Bladder-symphysis distance, mm (SD) & $25.7(7.92)$ & $27.9(8.24)$ & .2 \\
$\quad$ At rest & $15.8(7.61)$ & $17.2(9.30)$ & .5 \\
After Valsalva maneuver & & & \\
Anorectal angle-symphysis distance, mm (SD) & $13.2(4.12)$ & $14.4(4.45)$ & .3 \\
At rest & $8.87(3.79)$ & $10.1(4.67)$ & .3 \\
After Valsalva maneuver & $5.27(0.86)$ & $5.34(0.86)$ & .7 \\
Mean urethral meatus amplitude, mm (SD) & & & \\
Retrovesical angle, degree (SD) & $105.6(19.5)$ & $105.3(23.0)$ & .7 \\
At rest & $105.5(19.5)$ & $117.7(131.0)$ & .7 \\
After Valsalva maneuver & $3.34(0.82)$ & $3.66(1.05)$ & .12 \\
Bladder wall thickness, mm (SD) & $7.30(1.39)$ & $7.65(1.35)$ & .2 \\
Mean thickness of the right puborectalis muscle, mm (SD) & $7.29(1.28)$ & $7.42(1.52)$ & .7 \\
Mean thickness of the left puborectalis muscle, mm (SD) & $2.30(0.63)$ & $2.58(0.64)$ & .04 \\
Mean thickness of the internal anal sphincter, mm (SD) & $3.20(1.25)$ & $3.32(1.49)$ & .8 \\
Mean thickness of the external anal sphincter, mm (SD) & $15.4(2.64)$ & $15.5(2.62)$ & .8 \\
Minimal hiatal dimension (SD) & $29.0(9)$ & $5.5(4)$ & .02 \\
Presence of avulsion - right puborectalis muscle, \% & $25.8(8)$ & $6.8(5)$ & .02 \\
Presence of avulsion - left puborectalis muscle, \% & 18.5 & 10.7 & .3 \\
Damage of levator ani muscle, \% & 23.3 & 4.8 & .008 \\
Post void residual urine, \% & 16.1 & 6.9 & .14 \\
OASIS, \% &
\end{tabular}

${ }^{a}$ Chi-squared test for categorical variables, $t$-test for continuous variables with parametric distribution, Kruskal-Wallis test for continuous variables with nonparametric distribution. SD: standard deviation; OASIS: obstetric anal sphincter injures.

the explored ultrasound measurements were expressed as continuous variable and no-specific cut-offs to define a given parameter as abnormal could be computed in view of the small number of included cases. Finally, it was not possible to integrate different measurements into a multiparametric predictive model for PFD in view of the short time at follow-up, small number of included cases and the prospective design of the study, use of a new noninvasive ultrasound technique and the multitude of ultrasound parameters explored anatomy represents its main strengths. Furthermore, the present study focused on the assessment of pelvic floor morphometry and function in women with low-grade perineal tears, while the previously published literature is principally focused on women with "high-grade vaginal tears" such as third and fourth degree of tears. In this scenario, the findings from this study highlights the need for more accurate screening tool for partial LAM injuries and PFD in women with "low-grade vaginal tears" who will take advantage of specific prophylactic and therapeutic programs in order to prevent the longterm consequences associated with these disorders. Finally, although several studies have investigated the pelvic floor structures after childbirth, to our knowledge, there are few studies utilizing 2DTPUS, 3D EVUS, and 3D EAUS.

Identification of women at higher risk of PFD after vaginal birth is fundamental. PFDs affect one-third of adult women in the USA [12], with considerable impact on their quality of life. Furthermore, $11-20 \%$ of women affected by POP will undergo surgical treatment during their life [33-35] and approximately 40\% will experience anatomical POP recurrence while about $10 \%$ will require reoperation due to symptoms occurrence $[36,37]$. Nowadays is clear the contribution of vaginal delivery in the development of PFD [38]. Despite the fact that the diagnosis of PFD after vaginal birth is challenging, identification of childbirth-related trauma in the delivery room is not always possible because these lesions may be occult at the time of delivery and preceded by a long preclinical phase [39].

LAM avulsion represents one of the main determinants of PFD in women after vaginal birth and it is classically defined as the detachment of the muscle from the os pubis after of vaginal delivery [21]. LAM avulsion has been associated with anterior and central compartment prolapse, thus highlighting the need for a prompt identification of such anomalies [40,41]. There are different degrees of avulsion, ranging from the loss of a few fascicles to disruption of the entire the muscle, with the risk of PFD being directly related to the severity of avulsion.

In the present study, the incidence of LAM avulsion in women undergoing episiotomy, first- and seconddegree vaginal tears were $4.8 \%, 16.2 \%$ and $19.3 \%$ respectively, significantly higher than controls. These findings are partially concordant with those reported by other studies. In the study by Shek et al. signs of 
LAM avulsion were detected in 8.4 and $28.9 \%$ of women with first- and second-degree-perineal tears, respectively [42]. Differences in inclusion criteria, pregnancy and fetal characteristics, such as gestational age at birth, maternal age, BMl, and type of ultrasound techniques adopted may account for such differences.

Oasis includes third- and fourth-degree perineal tears and may lead to significant comorbidities, including anal incontinence, rectovaginal fistula, and pain. Furthermore, Oasis can have a significant impact on both short- and long-term quality of life and has been also associated with sexual dysfunction, dyspareunia and loss of bowel control [43]. Oasis commonly presents immediately after birth with an obvious perineal laceration following vaginal delivery (immediate Oasis) and confirmed at physical examination. However, some women present with signs of or anal sphincter injury only 6-8 weeks after vaginal delivery (post-partum Oasis) or later the post-partum period (occult Oasis). There is no consensus on o whether or when women should be routinely screened for Oasis after delivery. Regarding imaging assessment for women at EAUS is considered the gold standard in the diagnosis of Oasis $[21,43,44]$.

Andrews et al. in a prospective trial commented that the majority of occult injuries probably represent missed diagnoses and recommend a better and more focused training to recognize Oasis [45]. The risk of occult Oasis in women affected by first and seconddegree perineal tears is difficult to estimate. In the present study, the incidence of Oasis was higher in women with first- and (4.8\%) second (10.8\%) perineal tears and episiotomy (6.5\%) compared to controls (0\%). Although such differences did not reach statistical significance, the small number of included may have reduced the power of the analysis. These findings highlight the need for large studies assessing the actual incidence of occult Oasis in women with less severe perineal tears or episiotomy and exploring whether dedicated ultrasound assessment of the pelvis can anticipate clinical symptoms.

The role of episiotomy in relation to PFDs is unclear. Such intervention is used as a routine care policy during births in some countries, in order to reduce the risk of severe perineal trauma, which can be associated with a multitude of adverse maternal outcome such as severe blood loss, pain, infection, and long-term urinary and fecal dysfunction. However, a recent systematic review including randomized controlled trials comparing episiotomy as needed (selective episiotomy) with routine episiotomy in terms of benefits and harms for mother and baby in women at low risk of instrumental delivery, did not find any strong indication which suggests its routine use in clinical practice in order to prevent major perineal trauma [46]. Furthermore, another systematic review showed no benefit from episiotomy for prevention of fecal and urinary incontinence or pelvic floor relaxation. Likewise, the authors did not find any evidence that episiotomy reduces impaired sexual function, while pain with intercourse was more common among women with episiotomy [47]. However, there was large heterogeneity in study designs, outcomes observed and times at follow-up among the included studies which might have affected the study findings.

In the present study, women undergoing episiotomy had a ticker external anal sphincter, while there was no substantial difference in the incidence of LAM between women receiving and those not receiving episiotomy, although the analysis was affected by the small number of included cases. However, the findings from this study seem to confirm that episiotomy is not a strong risk factor for LAM avulsion and PFD although more powered studies are needed in order to elucidate the actual role of such procedure in affecting the short- and long-term pelvic function after vaginal birth.

Fundal pressure during the second stage of labor (also known as the "Kristeller maneuver") involves application of manual pressure to the uppermost part of the uterus directed towards the birth canal, in order to avoid prolonged second stage of labor and need for operative birth $[48,49]$. Kristeller maneuver is used in clinical practice although the benefits of such approach have still to be completely elucidate yet. A recent Cochrane systematic review including five randomized trials, found no difference in either spontaneous vaginal birth within a specified time, need for instrumental births, caesarean births, operative birth, duration of second stage, low arterial cord $\mathrm{pH}$ in newborn babies, or Apgar scores less than 7 at $5 \mathrm{~min}$. Furthermore, women receiving Kristeller maneuvers during the second stage of labor had a higher risk of cervical tears than in the control group [32].

In the present study, LAM avulsion was higher in women receiving compared to those not receiving Kristeller maneuver during second stage of labor. These findings are in accordance with those by Youssef et al. which reported a higher incidence of LAM avulsion in women receiving Kristeller compared to controls (28.4 versus $14.1 \%$ ), thus highlighting the need of dedicated assessment of pelvic floor functions in women receiving such maneuvers and discourage this practice [50]. 
In conclusion, 3D rotational ultrasound has the potential to show subtle signs of PFD in pregnancies complicated by first- or second-degree perineal tears or episiotomy 3 months after birth. However, the long-term implications of such findings and their actual impact on the quality of life of these women should be carefully evaluated because abnormal pelvic imaging may not directly translate into significant clinical symptoms.

Further large prospective studies are needed to validate the use of 3D rotational ultrasound as a noninvasive screening tool for PFD in women after vaginal birth and to build multiparametric predictive models integrating pregnancy and labor characteristics, pelvic imaging, and clinical assessment which can more accurately identify women at high risk for PFD, in order to prevent progression towards more severe anatomical and functional pelvic damage.

\section{Disclosure statement}

No potential conflict of interest was reported by the authors.

\section{ORCID}

Danilo Buca (iD http://orcid.org/0000-0001-6880-7407

Giuseppe Rizzo (D) http://orcid.org/0000-0002-5525-4353

Alexander Makatsariya (iD http://orcid.org/0000-0001-

7415-4633

Francesco D'Antonio (D) http://orcid.org/0000-0002-

5178-3354

\section{References}

[1] Haylen BT, de Ridder D, Freeman RM, et al. An international urogynecological association (IUGA)/international continence society (ICS) joint report on the terminology for female pelvic floor dysfunction. Neurourol Urodyn. 2009:21(1):5-26.

[2] Handa VL, Blomquist JL, Knoepp LR, et al. Pelvic floor disorders 5-10 years after vaginal or cesarean childbirth. Obstet Gynecol. 2011;118(4):777-784.

[3] MacLennan AH, Taylor AW, Wilson $\mathrm{DH}$, et al. The prevalence of pelvic floor disorders and their relationship to gender, age, parity and mode of delivery. BJOG. 2000;107(12):1460-1470.

[4] Mant J, Painter R, Vessey M. Epidemiology of genital prolapse: observations from the Oxford Family Planning Association Study. BJOG. 1997;104(5): 579-585.

[5] Hansen BB, Svare J, Viktrup L, et al. Urinary incontinence during pregnancy and 1 year after delivery in primiparous women compared with a control group of nulliparous women. Neurourol Urodyn. 2012;31(4): 475-480.
[6] Kepenekci I, Keskinkilic B, Akinsu F, et al. Prevalence of pelvic floor disorders in the female population and the impact of age, mode of delivery, and parity. Dis Colon Rectum. 2011;54(1):85-94.

[7] Memon H, Handa VL. Pelvic floor disorders following vaginal or cesarean delivery. Curr Opin Obstet Gynecol. 2012;24(5):349-354.

[8] Wu JM, Hundley AF, Fulton RG, et al. Forecasting the prevalence of pelvic floor disorders in U.S. Women: 2010 to 2050. Obstet Gynecol. 2009;114(6):1278-1283.

[9] Kim S, Harvey MA, Johnston S. A review of the epidemiology and pathophysiology of pelvic floor dysfunction: do racial differences matter? J Obstet Gynaecol Can. 2005;27(3):251-259.

[10] Torrisi G, Minini G, Bernasconi F, et al. A prospective study of pelvic floor dysfunctions related to delivery. Eur J Obstet Gynecol Reprod Biol. 2012;160(1): 110-115.

[11] Memon HU, Handa VL. Vaginal childbirth and pelvic floor disorders. Womens Health (Lond Engl). 2013; 9(3):265-277.

[12] Nygaard I, Barber MD, Burgio KL. Prevalence of symptomatic pelvic floor disorders in US women. JAMA. 2008;300(11):1311-1316.

[13] Friedman S, Blomquist JL, Nugent JM, et al. Pelvic muscle strength after childbirth. Obstet Gynecol. 2012;120:1021-1028.

[14] Dietz HP, Steensma AB. The prevalence of major abnormalities of the levator ani in urogynaecological patients. BJOG. 2006;113(2):225-230.

[15] Morgan DM, Cardoza P, Guire K, et al. Levator ani defect status and lower urinary tract symptoms in women with pelvic organ prolapse. Int Urogynecol J. 2010;21(1):47-52.

[16] Dietz HP, Shek C, Clarke B. Biometry of the pubovisceral muscle and levator hiatus by three-dimensional pelvic floor ultrasound. Ultrasound Obstet Gynecol. 2005;25(6):580-585.

[17] Valsky DV, Yagel S. Three-dimensional transperineal ultrasonography of the pelvic floor. J Ultrasound Med. 2007;26(10):1373-1387.

[18] Dietz HP, Simpson JM. Levator trauma is associated with pelvic organ prolapse. BJOG. 2008;115(8): 979-984.

[19] Yousuf AA, DeLancey JOL, Brandon CJ, et al. Pelvic structure and function at 1 month compared to 7 months by dynamic magnetic resonance after vaginal birth. Am J Obstet Gynecol. 2009;201(5): 514.e1-514.e7.

[20] Rostaminia G, Peck JD, Quiroz LH, et al. How well can levator ani musclemorphology on 3D pelvic floor ultrasound predict the levator ani muscle function? Int Urogynecol J. 2015;26(2):257-262.

[21] Santoro GA, Wieczorek AP, Dietz HP, et al. State of the art: an integrated approach to pelvicfloor ultrasonography. Ultrasound Obstet Gynecol. 2011;37(4): 381-396.

[22] Santoro GA, Wieczorek AP, Stankiewicz A, et al. Highresolution three-dimensional endovaginal ultrasonography in the assessment of pelvic floor anatomy: a preliminary study. Int Urogynecol J. 2009;20(10): 1213-1222. 
[23] Dietz HP, Steensma AB. Posterior compartment prolapse on two-dimensional and three-dimensional pelvic floor ultrasound: the distinction between true rectocele, perineal hypermobility and enterocele. Ultrasound Obstet Gynecol. 2005;26(1):73-77.

[24] Raimondo D, Youssef A, Mabrouk M, et al. Pelvic floor muscle dysfunction on 3D/4D transperineal ultrasound in patients with deep infiltrating endometriosis: a pilot study. Ultrasound Obstet Gynecol. 2017; 50(4):527-532.

[25] Dietz HP. Pelvic floor ultrasound: a review. Am J Obstet Gynecol. 2010;202(4):321-334.

[26] Tunn R, Schaer G, Peschers U, et al. Updated recommendations on ultrasonography in urogynecology. Int Urogynecol J. 2005;16(3):236-241.

[27] Dietz HP. Ultrasound imaging of the pelvic floor. Part I: two-dimensional aspects. Ultrasound Obstet Gynecol. 2004;23(1):80-92.

[28] Khullar V, Cardozo LD, Salvatore S, et al. Ultrasound: a noninvasive screening test for detrusor instability. BJOG. 1996;103(9):904-908.

[29] Lekskulchai O, Dietz HP. Detrusor wall thickness as a test for detrusor overactivity in women. Ultrasound Obstet Gynecol. 2008;32(4):535-539.

[30] van Delft K, Shobeiri SA, Thakar R, et al. Intra- and interobserver reliability of levator ani muscle biometry and avulsion using three-dimensional endovaginal ultrasonography. Ultrasound Obstet Gynecol. 2014; 43(2):202-209.

[31] Santoro GA, Wieczorek AP, Shobeiri SA, et al. Interobserver and interdisciplinary reproducibility of 3D endovaginal ultrasound assessment of pelvic floor anatomy. Int Urogynecol J Pelvic Floor Dysfunct. 2011;22(1):53-59.

[32] Hofmeyr GJ, Vogel JP, Cuthbert A, et al. Fundal pressure during the second stage of labour. Cochrane Database Syst Rev. 2017;3:CD006067.

[33] Olsen AL, Smith VJ, Bergstrom JO, et al. Epidemiology of surgically managed pelvic organ prolapse and urinary incontinence. Obstet Gynecol. 1997;89(4):501-506.

[34] Smith FJ, Holman CDJ, Moorin RE, et al. Lifetime risk of undergoing surgery for pelvic organ prolapse. Obstet Gynecol. 2010;116(5):1096-1100.

[35] de Boer TA, Slieker-Ten Hove MCP, Burger CW, et al. The prevalence and factors associated with previous surgery for pelvic organ prolapse and/or urinary incontinence in a cross-sectional study in the Netherlands. Eur J Obstet Gynecol Reprod Biol. 2011; 158(2):343-349.
[36] van Delft K, Sultan AH, Thakar R, et al. The relationship between postpartum levator ani muscle avulsion and signs and symptoms of pelvic floor dysfunction. BJOG. 2014;121(9):1164-1172.

[37] Miedel A, Tegerstedt G, Mörlin B, et al. A 5-year prospective follow-up study of vaginal surgery for pelvic organ prolapse. Int Urogynecol J. 2008;19(12): 1593-1601.

[38] Lukacz ES, Lawrence JM, Contreras R, et al. Parity, mode of delivery, and pelvic floor disorders. Obstet Gynecol. 2006;107(6):1253-1260.

[39] Dietz HP, Gillespie AV, Phadke P. Avulsion of the pubovisceral muscle associated with large vaginal tear after normal vaginal delivery at term. Aust $\mathrm{N} \mathrm{Z} \mathrm{J}$ Obstet Gynaecol. 2007;47(4):341-344.

[40] Dietz HP. Quantification of major morphological abnormalities of the levator ani. Ultrasound Obstet Gynecol. 2007;29(3):329-334.

[41] Dietz HP. Does bladder neck descent increase with age? Int Urogynecol J Pelvic Floor Dysfunct. 2007; 18(6):665-669.

[42] Shek KL, Green K, Hall J, et al. Perineal and vaginal tears are clinical markers for occult levator ani trauma: a retrospective observational study. Ultrasound Obstet Gynecol. 2016;47(2):224-227.

[43] Harvey MA, Pierce M, Walter JE, et al. Obstetrical anal sphincter injuries (Oasis): prevention, recognition, and repair. J Obstet Gynaecol Can. 2015;37(12):1131-1148.

[44] Sultan AH, Kamm MA, Talbot IC, et al. Anal endosonography for identifying external sphincter defects confirmed histologically. $\mathrm{Br} J$ Surg. 1994;81(3): 463-465.

[45] Andrews V, Sultan AH, Thakar R, et al. Occult anal sphincter injuries-myth or reality? BJOG. 2006;113(2): 195-200.

[46] Jiang H, Qian X, Carroli G, et al. Selective versus routine use of episiotomy for vaginal birth. Cochrane Database Syst Rev. 2017;2:CD000081.

[47] Hartmann K, Viswanathan M, Palmieri $R$, et al. Outcomes of routine episiotomy. JAMA. 2005;293(17) 2141-2148.

[48] Gynäkologe KS. Die Expressio foetus. Monatsschr Geburtskunde. 1867;8:337-387.

[49] Kline-Kaye V, Miller-Slade D. The use of fundal pressure during the second stage of labor. J Obstet Gynecol Neonat Nurs. 1990;19(6):511-517.

[50] Youssef A, Salsi G, Cataneo I, et al. Fundal pressure in second stage of labor (Kristeller maneuver) is associated with increased risk of levator ani muscle avulsion. Ultrasound Obstet Gynecol. 2019;53(1):95-100. 
Supplementary Table 1. Comparison of post-partum ultrasonographic and functional parameters between: (1) women with first degree vaginal tear and women with second degree vaginal tear; (2) women with first degree vaginal tear and women undergoing episiotomy; (3) women with second degree vaginal tear and women undergoing episiotomy during delivery.

\begin{tabular}{|c|c|c|c|c|}
\hline & $\begin{array}{l}\text { First degree } \\
\text { vaginal tear } \\
\qquad(n=21)\end{array}$ & $\begin{array}{l}\text { Second degree } \\
\begin{array}{r}\text { vaginal tear } \\
(n=37)\end{array}\end{array}$ & $\begin{array}{r}\text { Episiotomy } \\
(n=30)\end{array}$ & $\mathbf{p}^{\varphi}$ \\
\hline \multicolumn{5}{|l|}{ Bladder neck- symphysis distance, $\mathrm{mm}$ (SD) } \\
\hline - At rest & $26.6(3.98)$ & $24.3(5.05)$ & $24.5(5.56)$ & \\
\hline - After Valsalva manoeuvre & $20.9(4.87)$ & $16.6(5.67)$ & $17.1(8.35)$ & $*$ \\
\hline \multicolumn{5}{|l|}{ Bladder- symphysis distance, $\mathrm{mm}(\mathrm{SD})$} \\
\hline - At rest & $30.7(6.67)$ & $27.5(6.40)$ & $24.3(8.10)$ & $*, * *$ \\
\hline - After Valsalva manoeuvre & $22.4(7.41)$ & $16.7(7.84)$ & $14.7(8.80)$ & $* *$ \\
\hline \multicolumn{5}{|l|}{ Anorectal angle-symphysis distance, $\mathrm{mm}(\mathrm{SD})$} \\
\hline - At rest & $15.2(4.12)$ & $14.6(4.72)$ & $12.4(4.43)$ & $*$ \\
\hline - After Valsalva manoeuvre & $12.5(4.69)$ & $9.54(4.01)$ & $8.12(3.94)$ & $* *$ \\
\hline Mean urethral meatus amplitude, mm (SD) & $5.50(0.86)$ & $5.27(0.75)$ & $5.21(0.82)$ & \\
\hline \multicolumn{5}{|l|}{ Retrovesical angle (SD) } \\
\hline - At rest & $108.8(25.7)$ & $104.8(20.8)$ & $104.7(26.1)$ & \\
\hline
\end{tabular}




\begin{tabular}{|c|c|c|c|}
\hline - After Valsalva manoeuvre & $110.2(31.4)$ & $135.5(17.6)$ & $96.9(28.7)$ \\
\hline Bladder wall thickness, mm (SD) & $3.45(0.95)$ & $3.67(0.96)$ & $3.42(0.91)$ \\
\hline $\begin{array}{l}\text { Mean thickness of the right pubo-rectalis muscle, } \mathrm{mm} \\
\text { (SD) }\end{array}$ & $7.29(1.15)$ & $7.60(1.36)$ & $7.62(1.52)$ \\
\hline Mean thickness of the left pubo-rectalis muscle, mm (SD) & $7.13(1.27)$ & $7.46(1.51)$ & $7.52(1.53)$ \\
\hline Mean thickness of the internal anal sphincter, mm (SD) & $2.56(0.66)$ & $2.54(0.62)$ & $2.42(0.73)$ \\
\hline Mean thickness of the external anal sphincter, mm (SD) & $3.3(1.57)$ & $3.10(1.10)$ & $3.46(1.45)$ \\
\hline Mean recto-vaginal septum thickness, mm (SD) & $2.10(0.66)$ & $2.16(0.69)$ & $2.16(0.58)$ \\
\hline Mean uterus length, mm (SD) & & & \\
\hline - At rest & $35.8(7.49)$ & $35.5(8.90)$ & $33.7(11.1)$ \\
\hline - After Valsalva manoeuvre & $28.2(7.91)$ & $27.7(8.80)$ & $25.0(9.0)$ \\
\hline $\begin{array}{l}\text { Minimal hiatal dimension } \\
\text { (SD) }\end{array}$ & $14.7(2.36)$ & $15.8(2.59)$ & $15.2(2.60)$ \\
\hline Presence of avulsion - right pubo-rectalis muscle, $\%$ & 4.8 & 16.2 & 20.0 \\
\hline Presence of avulsion - left pubo-rectalis muscle, $\%$ & 9.5 & 16.2 & 20.0 \\
\hline
\end{tabular}




\begin{tabular}{|l|r|r|r|r|}
\hline Damage of levator ani muscle, \% & 7.1 & 19.3 & 10.7 & \\
\hline Post void residual urine, \% & 5.9 & 3.0 & 24.1 & $* * *$ \\
\hline OASIS, \% & 0 & & 6.7 & \\
\hline & & & & \\
\hline
\end{tabular}


Supplementary Table 2. Post-partum ultrasonographic parameters in the group of women reporting pelvic floor trauma during delivery, overall and by outcome.

\begin{tabular}{|c|c|c|c|c|c|}
\hline & Overall & Episiotomy & $\begin{array}{l}\text { First degree } \\
\text { vaginal tear }\end{array}$ & $\begin{array}{c}\text { Second degree } \\
\text { vaginal tear }\end{array}$ & $\begin{array}{l}\text { Kristeller } \\
\text { maneuver }\end{array}$ \\
\hline \multicolumn{6}{|l|}{ Right puborectalis muscle avulsion: } \\
\hline - Mean avulsion area, mm (SD) & $0.32(0.15)$ & $0.38(0.11)$ & $0.17(0.0)$ & $0.32(0.17)$ & $0.32(0.12)$ \\
\hline - Mean avulsion angle, $\mathrm{mm}$ (SD) & $22.0(6.02)$ & $22.4(9.81)$ & $20.0(0.0)$ & $24.8(6.44)$ & $24.8(6.01)$ \\
\hline - Mean avulsion thickness, in mm (SD) & $3.59(2.02)$ & $4.10(3.09)$ & $3.70(0.0)$ & $2.90(1.16)$ & $3.76(2.91)$ \\
\hline \multicolumn{6}{|l|}{ Left puborectalis muscle avulsion: } \\
\hline - Mean avulsion area, mm (SD) & $0.24(0.14)$ & $0.22(0.16)$ & $0.11(0.01)$ & $0.25(0.12)$ & $0.21(0.16)$ \\
\hline - Mean avulsion angle, mm (SD) & $22.9(7.55)$ & $19.0(5.93)$ & $16.7(2.54)$ & $25.8(6.86)$ & $25.0(8.66)$ \\
\hline - Mean avulsion thickness, mm (SD) & $3.45(2.14)$ & $2.38(2.41)$ & $4.35(1.62)$ & $3.15(0.44)$ & $1.96(1.25)$ \\
\hline \multicolumn{6}{|l|}{ Levator ani muscle damage: } \\
\hline - Mean area of damage, mm (SD) & $0.40(0.34)$ & $0.36(0.36)$ & $0.25(0.0)$ & $0.36(0.32)$ & $0.33(0.28)$ \\
\hline - Mean angle of damage, mm (SD) & $27.3(11.6)$ & $18.3(9.48)$ & $42.6(0.0)$ & $26.4(8.98)$ & $22.4(9.50)$ \\
\hline - Mean thickness, mm (SD) & $4.61(7.30)$ & $3.20(0.70)$ & $4.40(0.0)$ & $1.78(2.05)$ & $1.92(1.82)$ \\
\hline Mean OASIS angle in mm (SD) & $25.7(13.8)$ & $17.0(2.40)$ & $12.0(0.0)$ & $26.3(6.08)$ & $19.1(6.03)$ \\
\hline
\end{tabular}




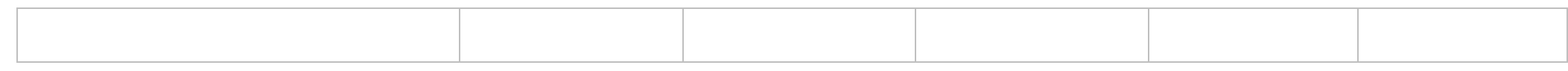

$\mathrm{SD}=$ Standard deviation. OASIS $=$ Obstetric Anal Sphincter Injures. 